Report Title: DEVELOPMENT OF IMPROVED CATALYSTS FOR THE SELECTIVE CATALYTIC REDUCTION OF NITROGEN OXIDES WITH HYDROCARBONS

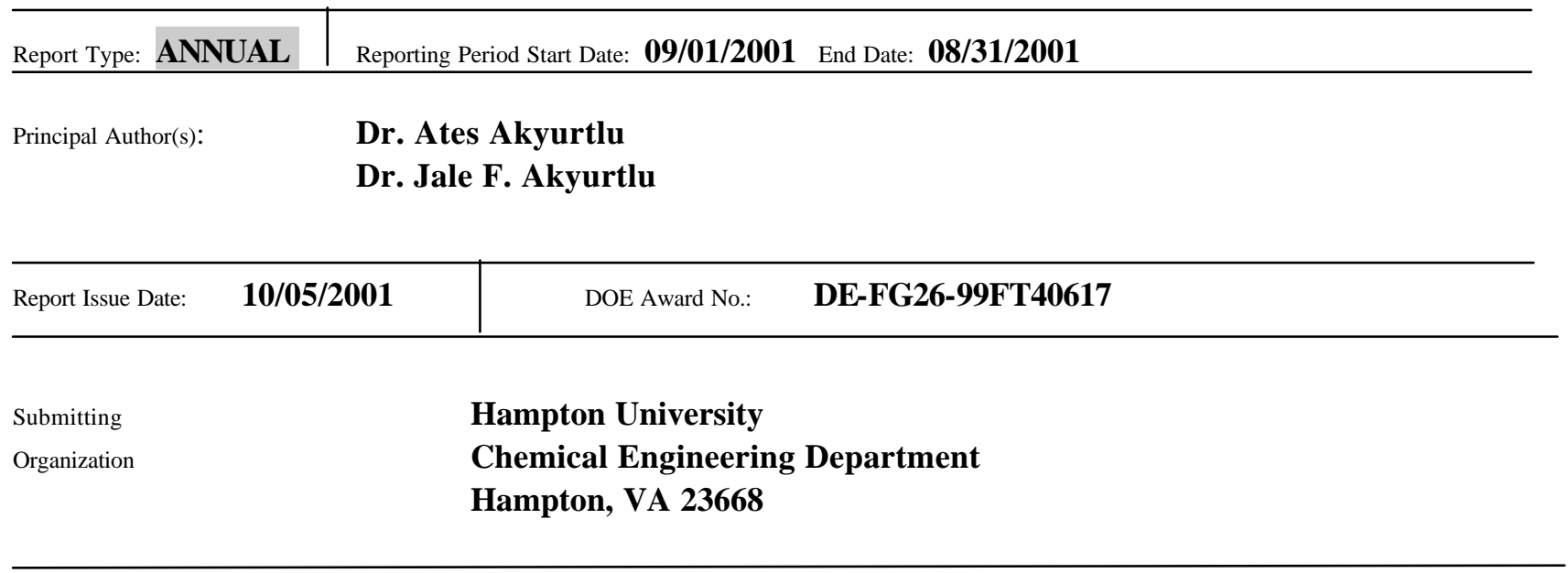




\section{DEVELOPMENT OF IMPROVED CATALYSTS FOR THE SELECTIVE CATALYTIC REDUCTION OF NITROGEN OXIDES WITH HYDROCARBONS}

GRANT AWARD NUMBER: DE-FG26-99FT40617

START DATE: September 1, 1999

EXPECTED COMPLETION DATE: August 31, 2002

PRINCIPAL INVESTIGATOR: Ates Akyurtlu

CO-INVESTIGATOR: Jale F. Akyurtlu

Department of Chemical Engineering

Hampton University

Hampton, VA 23668

Annual Technical

Progress Report

September 2001 


\section{DISCLAIMER}

“This report was prepared as an account of work sponsored by an agency of the United States Government. Neither the United States Government nor any agency thereof, nor any of their employees, makes any warranty, expressed or implied, or assumes any legal liability or responsibility for the accuracy, completeness, or usefulness of any information, apparatus, product, or process disclosed, or represents that its use would not infringe privately owned rights. Reference herein to any specific commercial product, process, or service by trade name, trademark, manufacturer, or otherwise does not necessarily constitute or imply its endorsement, recommendation, or favoring by the United States Government or any agency thereof. The views and opinions of authors expressed herein do not necessarily state or reflect those of the United States Government or any agency thereof." 


\begin{abstract}
Significant work has been done by the investigators on the cerium oxide-copper oxide based sorbent/catalysts for the combined removal of sulfur and nitrogen oxides from the flue gases of stationary sources. A relatively wide temperature window was established for the use of alumina-supported cerium oxide-copper oxide mixtures as regenerable sorbents for $\mathrm{SO}_{2}$ removal. Preliminary evaluation of these sorbents as catalysts for the selective reduction of $\mathrm{NO}_{\mathrm{x}}$ gave promising results with ammonia, but indicated low selectivity when methane was used as the reductant. Since the replacement of ammonia by another reductant is commercially very attractive, in this project, four research components will be undertaken.

The investigation of the reaction mechanism, the first component, will help in the selection of promoters to improve the catalytic activity and selectivity of the sorbents in the SCR with methane. This will result in new catalyst formulations (second component). If this research is successful, the combined $\mathrm{SO}_{2}-\mathrm{NO}_{\mathrm{x}}$ removal process based on alumina-supported copper oxide-ceria sorbent/catalysts will become very attractive for commercial applications. The objective of the third component of the project is to develop an alternative SCR process using another inexpensive fuel, residual fuel oil, instead of natural gas. This innovative proposal is based on very scant evidence concerning the good performance of coked catalysts in the selective reduction of NO and if proven to work the process will certainly be commercially viable. The fourth component of the project involves our industrial partner TDA Research, and the objective is to evaluate long- term stability and durability of the prepared sorbent/catalysts.

In the second year of the project, the catalysts were investigated for their SCR activity with methane in a microreactor setup and also, by the temperature-programmed desorption (TPD) technique. The results from the SCR experiments indicated that manganese is a more effective promoter than rhodium on the supported copper oxide-ceria catalysts under study; the effectiveness of the promoter increases with the increase in $\mathrm{Ce} / \mathrm{Cu}$ ratio. The TPD profiles of the unpromoted catalyst $(\mathrm{Cu} / \mathrm{Ce}=3)$ is different than those promoted with $0.1 \%$ rhodium.
\end{abstract}




\section{TABLE OF CONTENTS}

\section{$\underline{\text { Page }}$}

Disclaimer

iii

Abstract

iii

Executive Summary

1

Work Done 3

I) Background Information 3

II) Experimental Work 5

III) Results and Discussion $\quad 9$

IV) Conclusions 22

V) Additional Activities 23

$\begin{array}{ll}\text { Future Plans } & 23\end{array}$ 


\section{EXECUTIVE SUMMARY}

Significant work has been done by the investigators on the cerium oxide-copper oxide based sorbent/catalysts for the combined removal of sulfur and nitrogen oxides from the flue gases of stationary sources. A relatively wide temperature window was established for the use of alumina-supported cerium oxide-copper oxide mixtures as regenerable sorbents for $\mathrm{SO}_{2}$ removal. Preliminary evaluation of these sorbents as catalysts for the selective reduction of $\mathrm{NO}_{\mathrm{x}}$ gave promising results with ammonia, but indicated low selectivity when methane was used as the reductant. Since the replacement of ammonia by another reductant is commercially very attractive, in this project, four research components will be undertaken:

- Investigation of the adsorption-reaction mechanism for the reduction of $\mathrm{NO}_{\mathrm{x}}$ by methane using temperature programmed desorption and temperature programmed reaction studies.

- Improvement of the activity and selectivity of alumina supported cerium oxide-copper oxide-based sorbent catalysts for the reduction of $\mathrm{NO}_{\mathrm{x}}$ by methane by the addition of promoters to enhance $\mathrm{NO}$ chemisorption, NO oxidation, intermediate stabilization, or methane activation. Alternative catalyst preparation methods will also be tried to enhance metal aluminate formation over the formation of oxide crystals.

- Investigation of the possibility of using inexpensive and widely available residual fuel oils as an alternate reductant to replace ammonia in the SCR reaction.

- Long term testing of the sorbent catalysts in a pilot size setup by TDA Research, our industrial partner.

The investigation of the reaction mechanism will help in the selection of promoters to improve the catalytic activity and selectivity of the sorbents in the SCR with methane. If this research is successful, the combined $\mathrm{SO}_{2}-\mathrm{NO}_{\mathrm{x}}$ removal process based on alumina-supported copper oxide-ceria sorbent/catalysts will become very attractive for commercial applications. The objective of the third component of the project is to develop an alternative SCR process using another inexpensive fuel, residual fuel oil, instead of natural gas. This innovative proposal is based on very scant evidence concerning the good performance of coked catalysts in the selective reduction of NO and if proven to work the process will certainly be commercially viable. The fourth component of the project involves our industrial partner TDA Research, and the objective is to evaluate long- term stability and durability of the prepared sorbent/catalysts. 
In the second year of the project, the catalysts were investigated for their SCR activity with methane in a microreactor setup and also, by the temperature-programmed desorption (TPD) technique. The results from the SCR experiments indicated that manganese is a more effective promoter than rhodium on the supported copper oxide-ceria catalysts under study; the effectiveness of the promoter increases with the increase in $\mathrm{Ce} / \mathrm{Cu}$ ratio. The TPD profiles of the unpromoted catalyst $(\mathrm{Cu} / \mathrm{Ce}=3)$ is different than those promoted with $0.1 \%$ rhodium. 


\section{WORK DONE}

\section{Background Information}

The sorbents (Table 1) consisting of cerium oxide and copper oxide impregnated on alumina were prepared and characterized during a previous research project funded by DOE (DE-FG2296PC96216). Their sulfation performance was investigated in a TGA setup, studying mainly the effects of temperature, sorbent composition, metal loading and support type. As a result of the sulfation experiments, a relatively wide temperature window was established for the use of alumina-supported cerium oxidecopper oxide as regenerable sorbents for sulfur dioxide removal. In the 723-823 K temperature range, cerium oxide-copper oxide sorbents have specific sorbent capacities (mass of sulfur removed per unit mass of metal sorbent) and sulfation rates significantly higher than those of cerium oxide and copper oxide sorbents used alone. Best sulfation performance was exhibited by the sorbent containing 1:1 molar ratio of cerium and copper. Specific sulfur capacities decreased as the coverage of the support surface by the metal oxides approached monolayer coverage. Sorbents appeared to be resistant to cycling. No loss of sulfation capacity was observed after the third cycle.

The evaluation of these sorbents for the selective reduction of $\mathrm{NO}_{\mathrm{x}}$ gave promising results with ammonia, but indicated low selectivity when methane was used as a reductant. In the reduction of NO with $\mathrm{NH}_{3}$, the conversion passes through a maximum at $573 \mathrm{~K}$. Selective catalytic reduction studies with methane indicated that NO conversions between $10 \%$ and $17 \%$ could be obtained in the temperature range 648-748 $\mathrm{K}$ on catalysts containing both copper and cerium oxides for the space velocity used in the experiments (13700/hr).

Since propylene is known to be a more active and selective reductant for NO with other SCR 
catalysts and since hydrocarbons are much more desirable reductants for NO removal, the performance of $\mathrm{Cu}-\mathrm{Ce}$ catalysts for SCR of NO with propylene was also investigated. Although propylene was found to be very active in the absence of oxygen, the NO conversions obtained in wet oxygen-containing gases was limited to the same range observed using methane. With propylene, the temperature for maximum NO conversion decreased as the $\mathrm{Cu} / \mathrm{Ce}$ ratio increased. Maximum conversion obtained was $17.5 \%$ at $713 \mathrm{~K}$ on the catalyst with $\mathrm{Cu} / \mathrm{Ce}=3(\mathrm{Cu} 7.5 \mathrm{Ce} 2.5)$. For $\mathrm{Cu} 8 \mathrm{Ce} 2$ and $\mathrm{Cu} 2 \mathrm{Ce} 6$ catalysts, the $\mathrm{NO}$ conversions obtained in wet oxygen-containing gases were limited to about $12.5 \%$ and $10.5 \%$ respectively, for the space velocities employed in this research (about 13,700/hour). This was due to low selectivity at high temperatures and low activity at low temperatures. In fact, the NO conversion passes through a maximum at around $730 \mathrm{~K}$ and $740 \mathrm{~K}$ for $\mathrm{Cu} 8 \mathrm{Ce} 2$ and $\mathrm{Cu} 2 \mathrm{Ce} 6$ catalysts, respectively. It was observed that water has a negative effect on NO conversion for $\mathrm{Cu}-\mathrm{Ce}$ catalysts; $\mathrm{NO}$ conversion reduces from $21 \%$ in the absence of water to $12.5 \%$ in the presence of $7 \%$ water on $\mathrm{Cu} 8 \mathrm{Ce} 2$ catalyst.

Table 1. Physical Properties of the Sorbent/Catalysts

\begin{tabular}{|l|c|c|c|c|c|}
\hline \multirow{2}{*}{ Sorbent } & \multicolumn{2}{|c|}{$\begin{array}{c}\text { Cerium Loading, } \\
\text { mass } \%\end{array}$} & \multicolumn{2}{c|}{$\begin{array}{c}\text { Copper Loading, } \\
\text { mass } \%\end{array}$} & \multirow{2}{*}{$\begin{array}{c}\text { Surface Area, } \\
\mathrm{m}^{2} / \mathrm{g}\end{array}$} \\
& \multirow{2}{*}{ Nominal } & Actual & Nominal & Actual & \\
\hline SOR10-II & 5 & 4.58 & 5 & 5.54 & 122 \\
\hline SOR10-III & 2.5 & 2.26 & 7.5 & 8.42 & 134 \\
\hline SOR10-IV & 7.5 & 6.49 & 2.5 & 2.77 & 122 \\
\hline SOR10-V & 2 & 1.90 & 8 & 8.76 & 130 \\
\hline SOR10-VI & 0 & 0 & 10 & 10.36 & 105 \\
\hline SOR 10-VII & 10 & & 0 & 0 & 126 \\
\hline
\end{tabular}




\section{Experimental}

(i) NO $\mathbf{x}_{\mathrm{x}}$ Removal

a) Catalysts

In the second year of the project, new catalysts were prepared in order to investigate their selective catalytic activity for the reduction of NO by methane by the promotion of some of the catalysts presented in Table 1. The catalysts were selected according to the observations summarized in Section I of this report. As promoters, rhodium and manganese were used. The new catalysts are:

1. SOR10-III-0.1\%RH

2. SOR10-III-1\%MN

3. SOR10-IV-0.1\%RH

4. SOR10-IV-1\%MN

These catalysts are prepared by the incipient wetness technique, by impregnating the base catalysts (SOR10-III and SOR10-IV) by the appropriate metal salts, rhodium(III) chloride hydrate and manganes (II) nitrate hydrate, purchased from Sigma-Aldrich Co. (Milwaukee, WI).

\section{b) Experimental Setup and Procedure}

The experimental setup used for the selective catalytic reduction of NO is presented in Figure 1. For $\mathrm{NO}_{\mathrm{x}}$ removal experiments, 2 grams of the catalyst/(sorbent) (particle size of 250 - 425 ìm) is weighed and placed in the quartz microreactor. The reactant gas mixture is prepared from high purity bottled gases without further purification. Methane is used as the reductant.

The reactant gas composition for the standard SCR experiments is 650-900 ppm NO, which contains a maximum of 5 ppm $\mathrm{NO}_{2}, 1.5 \% \mathrm{O}_{2}, 7 \% \mathrm{H}_{2} \mathrm{O}, \mathrm{CH}_{4} / \mathrm{NO}$ molar ratio of 1 , and balance He. 
Temperature range is $573-798 \mathrm{~K}$. 


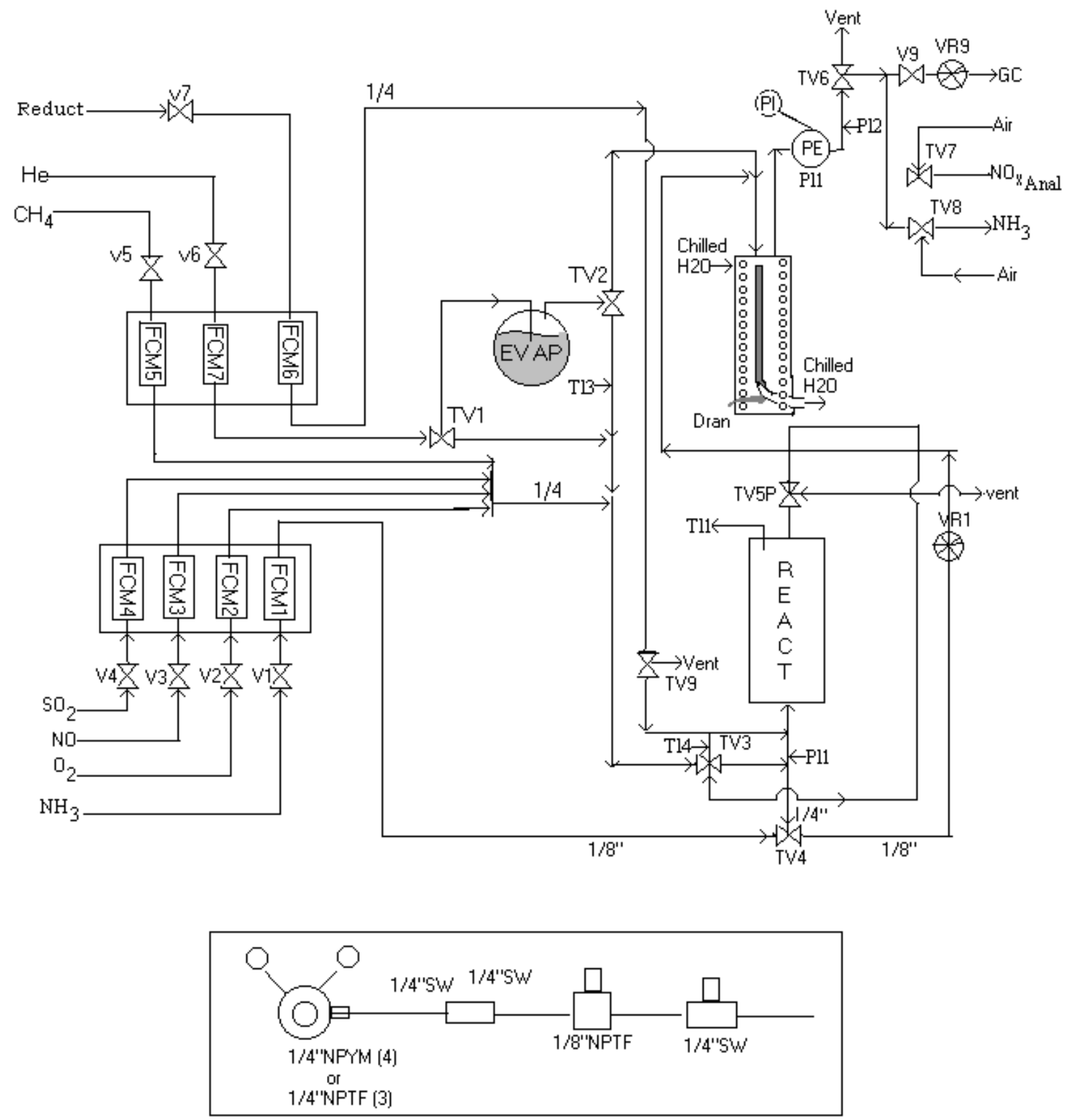

FIGURE 1. Experimental Setup for $\mathrm{NO}_{\mathrm{x}}$ Removal Experiments 
Gas samples were analyzed using a Varian $3400 \mathrm{Gas}$ Chromatograph for $\mathrm{CO}, \mathrm{CO}_{2}, \mathrm{~N}_{2}, \mathrm{O}_{2}, \mathrm{CH}_{4}$ and $\mathrm{C}_{3} \mathrm{H}_{6}$. For the first five components, TCD detector with a 15' Carboxen 1000 column from Supelco was used. The column was temperature-programmed for the optimum resolution of the components; it was kept at $35^{\circ} \mathrm{C}$ for 5 minutes, then heated to $225^{\circ} \mathrm{C}$ at $20^{\circ} \mathrm{C} /$ minute and kept at that temperature for 10 minutes. Under these conditions, the retention times were $5.5 \mathrm{~min}$ for $\mathrm{O}_{2}, 6 \mathrm{~min}$ for $\mathrm{N}_{2}, 7.7 \mathrm{~min}$ for $\mathrm{CO}$, 11.5 min for $\mathrm{CH}_{4}$, and 13.8 min for $\mathrm{CO}_{2}$.

A Thermo Environmental Instruments Model $42 \mathrm{H}$ Chemiluminescence $\mathrm{NO}-\mathrm{NO}_{2}-\mathrm{NO}_{\mathrm{x}}$ analyzer was employed for the quantitative analysis of $\mathrm{NO}_{2}$ and NO. In the presence of a reductant, the high temperature $(923 \mathrm{~K})$ converter in the instrument leads to side reactions and gives erroneous $\mathrm{NO}_{2}$ and $\mathrm{NO}_{\mathrm{x}}$ readings. To overcome this shortcoming, the low temperature $(623 \mathrm{~K})$ Mo converter is utilized. With this converter reliable $\mathrm{NO}_{2}$ measurements can be made.

$$
\begin{array}{ll}
4 \mathrm{NO}+\mathrm{CH}_{4} & 2 \mathrm{~N}_{2}+\mathrm{CO}_{2}+2 \mathrm{H}_{2} \mathrm{O} \\
\mathrm{CH}_{4}+2 \mathrm{O}_{2} & \mathrm{CO}_{2}+2 \mathrm{H}_{2} \mathrm{O} \\
2 \mathrm{CH}_{4}+\mathrm{N}_{2} & 2 \mathrm{NH}_{3}+\mathrm{H}_{2}+2 \mathrm{C}
\end{array}
$$

The results from the $\mathrm{NO}_{\mathrm{x}}$ removal experiments are interpreted by calculating the conversion of $\mathrm{NO}_{\mathrm{x}}$ as:

$$
\mathrm{NO} \text { conversion }\left(\mathrm{X}_{\mathrm{NO}}\right)=[\mathrm{NO} \text { in feed }-\mathrm{NO} \text { in reactor effluent }] /[\mathrm{NO} \text { in feed }]
$$

\section{(ii) Temperature-Programmed Desorption Experiments}

In the investigation of the mechanism of selective catalytic reduction reaction, one approach is to use Temperature-Programmed Desorption (TPD) Experiments in order to evaluate the $\mathrm{NO}, \mathrm{NO}_{2}$, and $\mathrm{O}_{2}$ chemisorption capacity of the catalysts and to identify the surface species and desorption species. For temperature-programmed experiments, a Micromeritics Pulse Chemisorb 2705 with TPD/TPR Option is used. A mass spectrometer-gas chromatograph system (SATURN 2000MS/3800GC) from Varian is used 
for the identification of desorbed species and reaction products.

A typical TPD run is described below:

1. Pretreat all the samples in $\mathrm{He}(20 \mathrm{ml} / \mathrm{min})$ at $323 \mathrm{~K}$ for 2 hours. This thermal treatment will prevent any appreciable oxygen uptake.

2. Carry out $\mathrm{NO}\left(\mathrm{NO}_{2}, \mathrm{NO}+\mathrm{O}_{2}, \mathrm{O}_{2}, \mathrm{CH}_{4}\right.$, or $\left.\mathrm{CH}_{4}+\mathrm{O}_{2}\right)$ adsorption at $323 \mathrm{~K}$ by flowing a $\mathrm{NO} / \mathrm{He}$ mixture (or a similar mixture containing other adsorbents) containing $1.93 \% \mathrm{NO}$ in $\mathrm{He}$, $3.6 \% \mathrm{O}_{2}$ in $\mathrm{He}, 2.03 \% \mathrm{CH}_{4}$ in $\mathrm{He}$.

Flow rate: $40 \mathrm{ml} / \mathrm{min}$

Temperature range: $35^{\circ} \mathrm{C}-700^{\circ} \mathrm{C}$

Temperature ramp: $3^{\circ} \mathrm{C} / \mathrm{min}$

3. Flush the sample with a stream of dry helium at $323 \mathrm{~K}$ to eliminate gaseous NO and weakly adsorbed NO (or any other adsorbent).

4. When no NO (or any other adsorbent) is observed, heat the sample to $973 \mathrm{~K}$ in flowing He stream. Record the desorbed species.

5. The amount of NO adsorbed on the catalyst will be determined either from the NO adsorption measurement and the desorbed surface species from the TPD profile by integrating the desorption rate versus time data.

6. Repeat this procedure for two more cycles. Cool the sample to $323 \mathrm{~K}$.

7. Adsorb methane at $323 \mathrm{~K}$, then helium for 30 minutes.

8. Adsorb NOe at $323 \mathrm{~K}$, then helium for 30 minutes.

9. Heat the sample up to $973 \mathrm{~K}$ in flowing helium stream for TPD. Cool the sample to $323 \mathrm{~K}$.

10. Adsorb oxygen at $323 \mathrm{~K}$, then helium for 30 minutes.

11. Adsorb methane at $323 \mathrm{~K}$, then helium for 30 minutes.

12. Heat the sample up to $973 \mathrm{~K}$ in flowing helium stream for TPD.

13. Regeneration: a) Treat with oxygen at $923 \mathrm{~K}$ for two hours; cool to $323 \mathrm{~K}$.

b) Treat with helium (saturated at $300 \mathrm{~K}$ ) at $323 \mathrm{~K}$ for 15 minutes. 


\section{Results and Discussion}

(i) $\quad \underline{\text { Results and Discussion of } \mathrm{NO}_{\underline{x}}} \underline{\text { Removal Experiments }}$

In the previous project, it was observed that NO conversions showed a maximum with temperature due to the effect of temperature on the rates of reductant $+\mathrm{NO}$ and reductant $+\mathrm{O}_{2}$ reactions, indicating that the reductant+ $\mathrm{NO}$ reaction has a smaller activation energy. It was also found that cerium oxide and copper oxide by themselves were not good catalysts for the reduction of NO with methane, especially at low temperatures. Maximum NO conversion at the space velocities used in the experiments (13700/hr) was 9 $\%$ at $475^{\circ} \mathrm{C}$ with cerium oxide and about $8 \%$ at $450^{\circ} \mathrm{C}$ for copper oxide. Catalysts containing both copper and cerium oxides had better activities for NO reduction with methane, regardless of the $\mathrm{Cu} / \mathrm{Ce}$ metal ratio. The maximum NO conversion at the space velocity used was about $17 \%$ obtained at $425^{\circ} \mathrm{C}$ with both SOR10-III $(\mathrm{Cu} / \mathrm{Ce}=3)$ and SOR10-IV $(\mathrm{Cu} / \mathrm{Ce}=1 / 3)$ catalysts, being slightly lower for the former.

The effect of promoters, $\mathrm{Mn}$ and $\mathrm{Rh}$, are investigated this year and the results of the NO reduction experiments on the promoted catalysts are presented in Figures 1-4. The conclusions that may be drawn from these figures are as follows:

1. With the SOR10-III $(\mathrm{Cu} / \mathrm{Ce}=3)$, the activity remained the same with promotion by rhodium compared to the unpromoted catalyst. However, manganese was an effective promoter, increasing the activity to $21.8 \%$ NO reduction compared to $16.5 \%$ with the unpromoted SOR10-III catalyst.

2. With the SOR10-IV $(\mathrm{Cu} / \mathrm{Ce}=1 / 3)$, the activity increased with promotion by both rhodium and manganese compared to the unpromoted catalyst, reaching to $20.7 \%$ by rhodium and $23.6 \%$ by manganese. 
Effect of promoter on catalyst activity is more pronounced on catalysts with higher $\mathrm{Ce} / \mathrm{Cu}$ ratio; this observation implies that the synergy is due to cerium rather than copper.

FIGURE 1. Reduction of NO by Methane on SOR10-III-0.1\% Rh

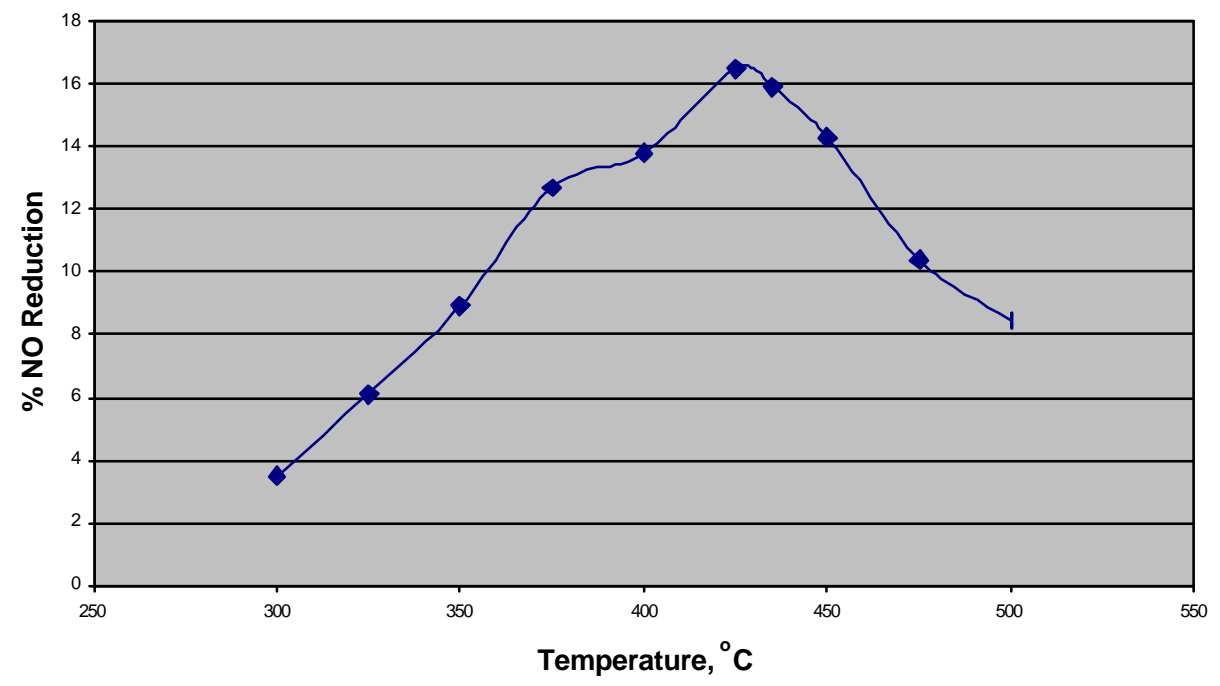


FIGURE 2. Reduction of NO by Methane on SOR10-III-1\% Mn

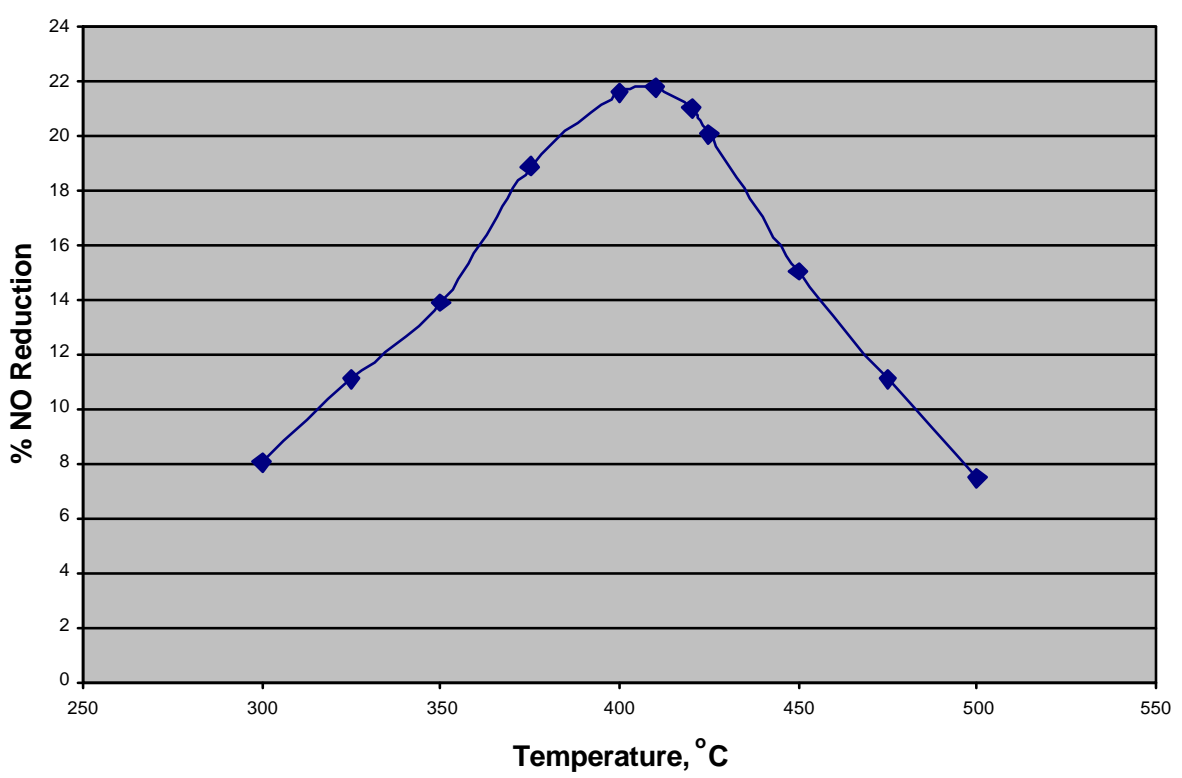

FIGURE 3. Reduction of NO by Methane on SOR10-IV-0.1\% Rh

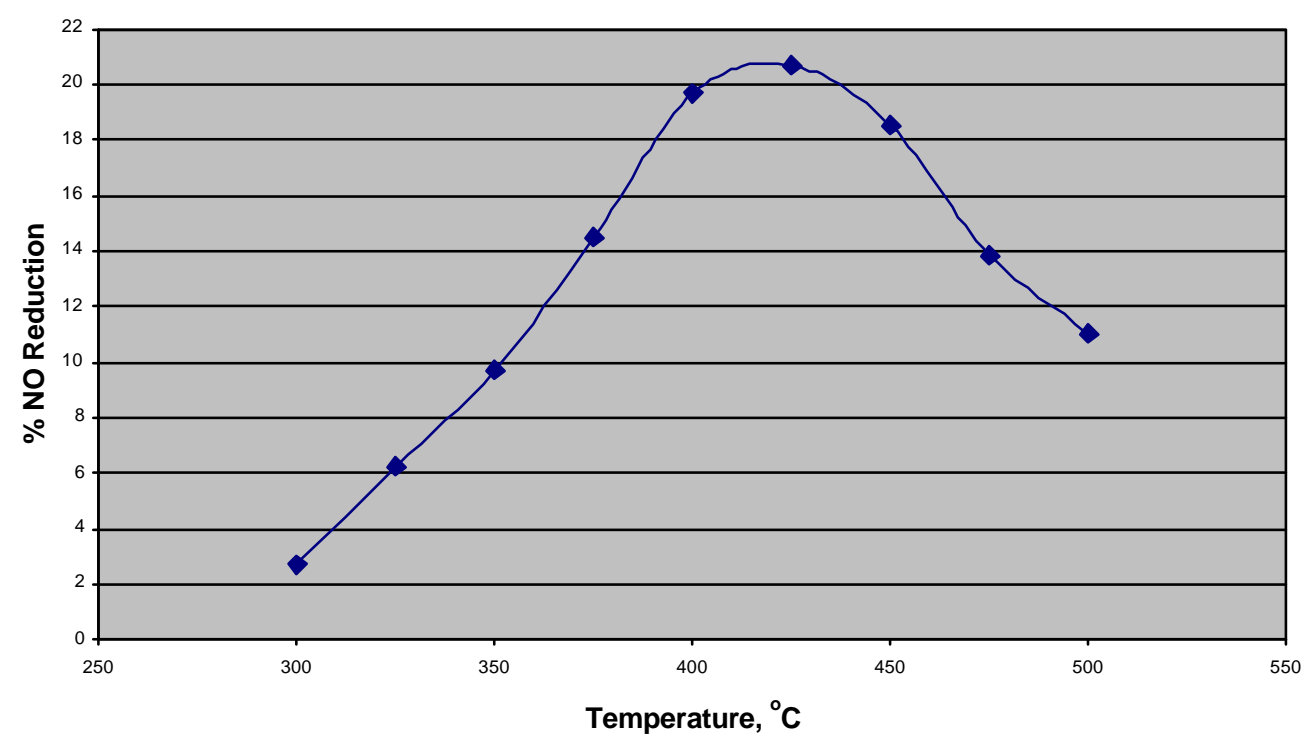


FIGURE 4. Reduction of NO by Methane on SOR10-IV-1\% Mn

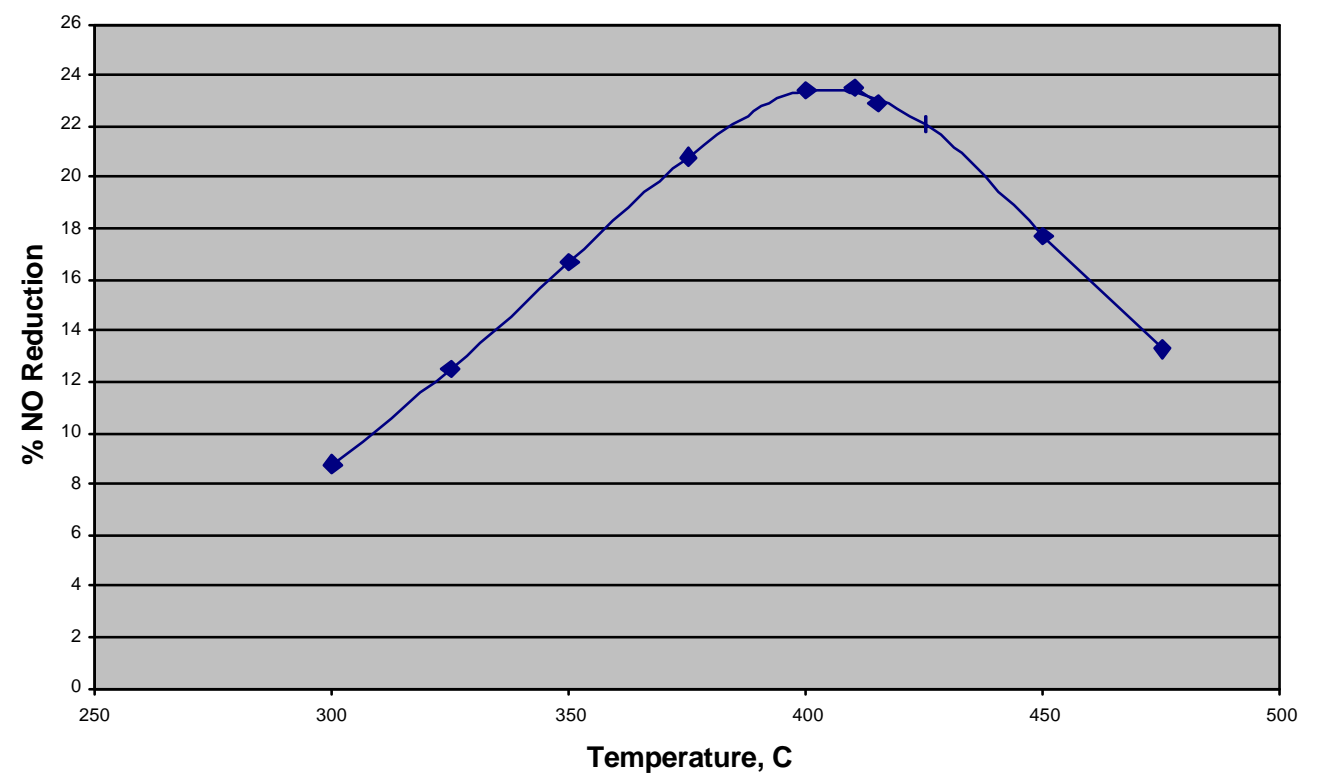


More promoted catalysts will be prepared to understand the reason for the different performance of promoters in the extent of $\mathrm{NO}$ reduction with catalysts with different $\mathrm{Cu} / \mathrm{Ce}$ ratios. These catalysts will also be subjected to TPD-TPR analysis to investigate the effects of various promoters on the catalyst performance.

(ii) Results and Discussion of Temperature-Programmed Desorption Experiments

The results from the TPD Experiments are presented in Figures 5-22.

FIGURE 5. TPD of Ce2.5Cu7.5 Catalyst After NO Adsorption (DTPD002-TPD)

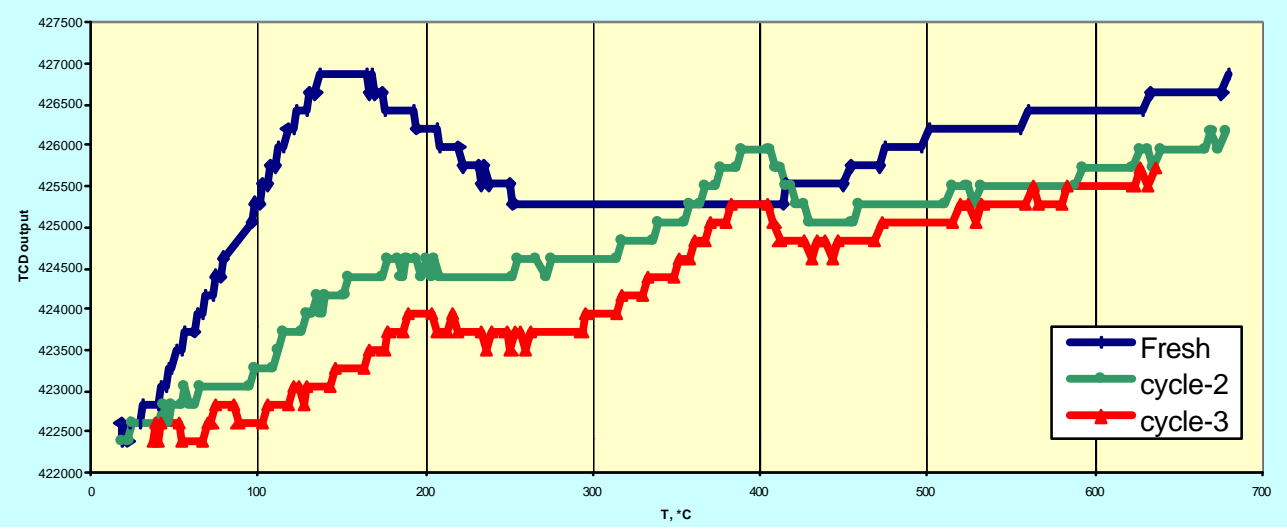


FIGURE 6. Evolved Species During TPD of Fresh Ce2.5Cu7.5 Catalyst After NO Adsorption. (DTPD002A)

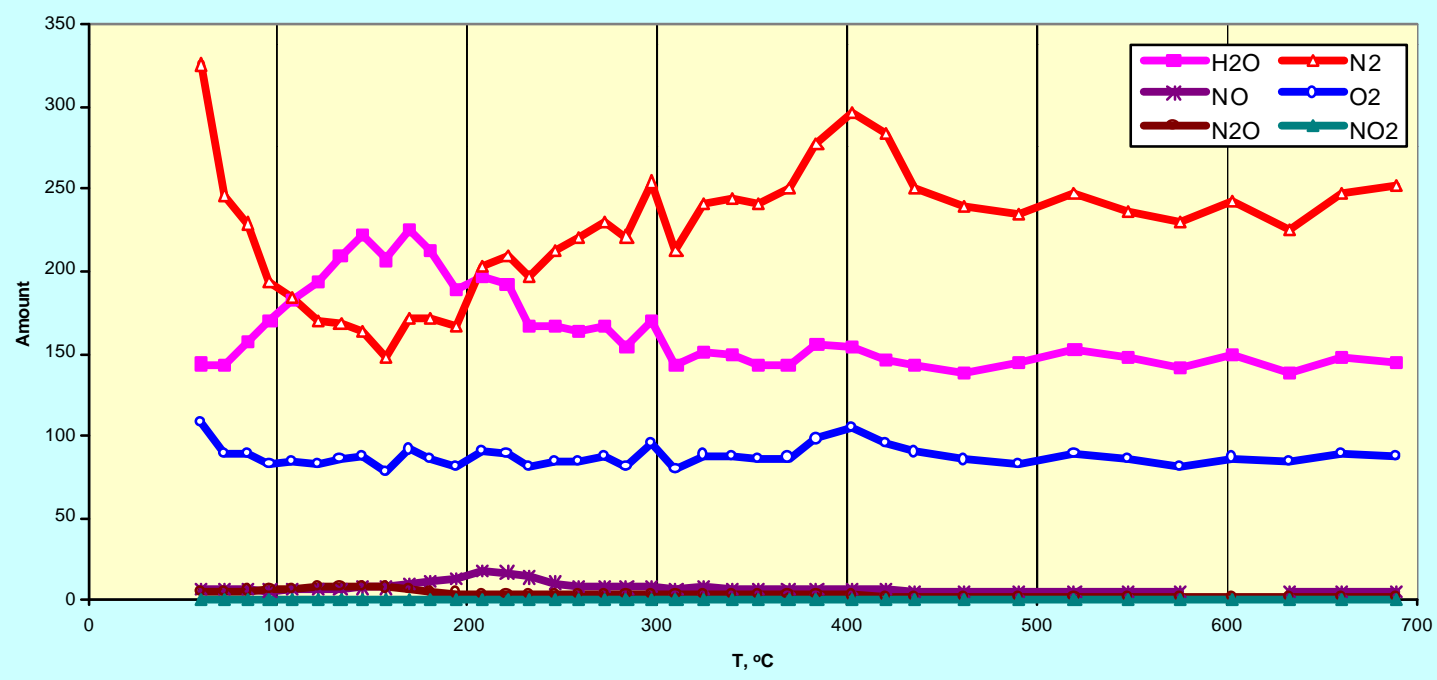

FIGURE 7. Evolved Species During TPD of Ce2.5Cu7.5 Catalyst After NO Adsorption. Cycle-2 (DTPD002C)

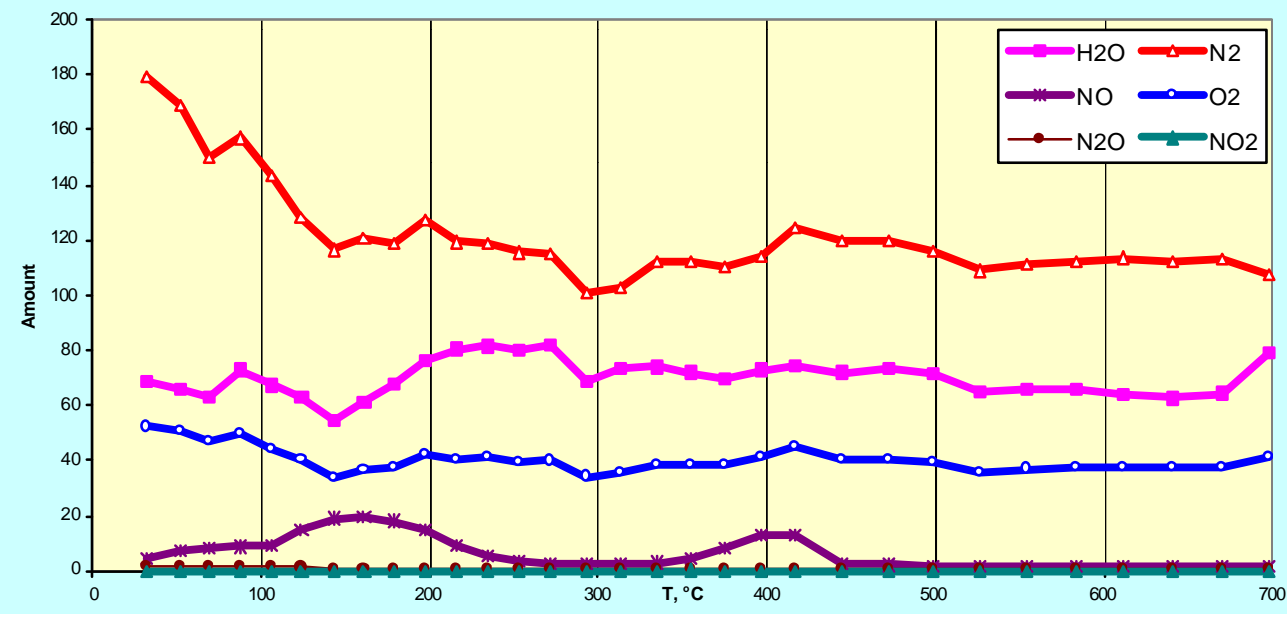


FIGURE 8. Evolved Species During TPD of Ce2.5Cu7.5 Catalyst After NO Adsorption. Cycle-3 (DTPD002D)

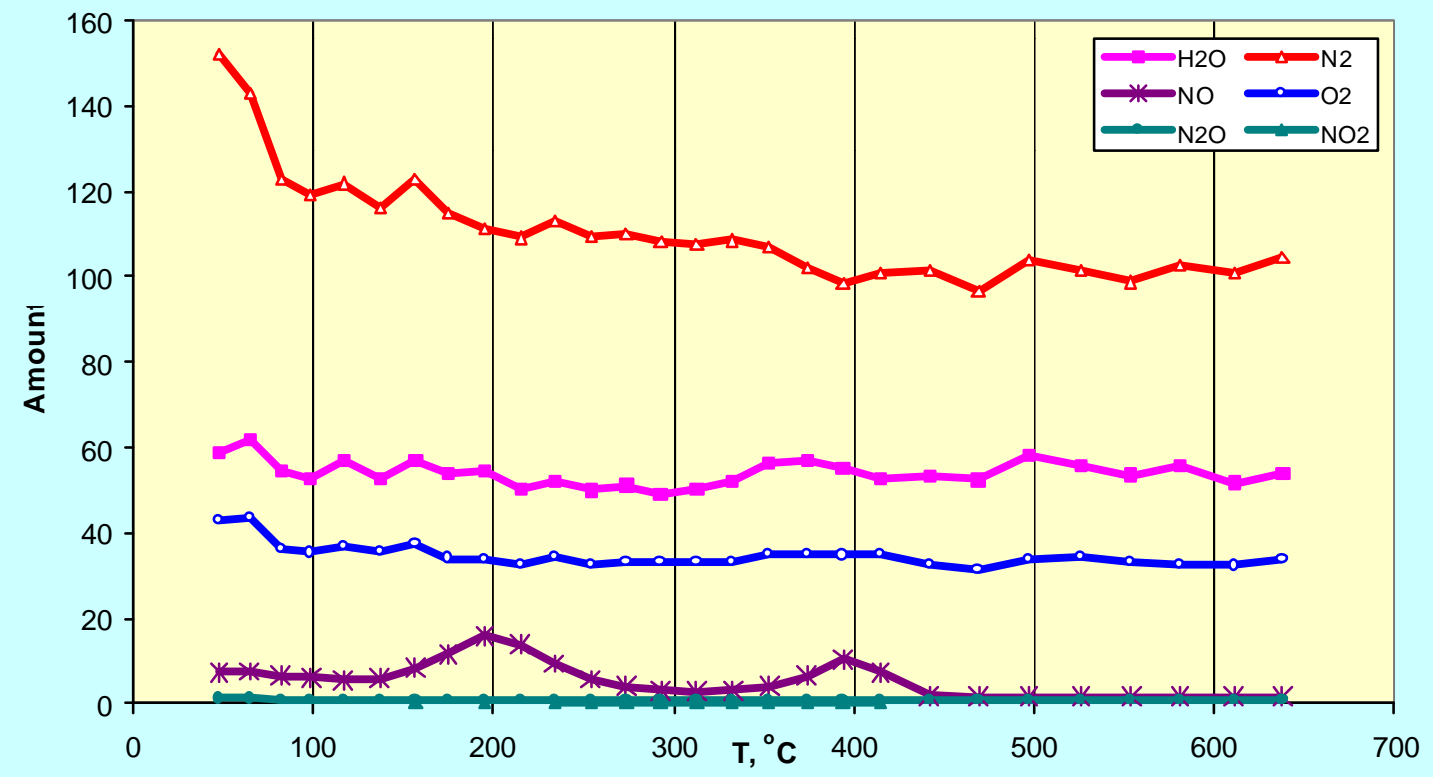


FIGURE 9. TPD of Ce2.5Cu7.5 Catalyst with $0.1 \%$ Rh After NO Adsorption (DTPD001-TPD)

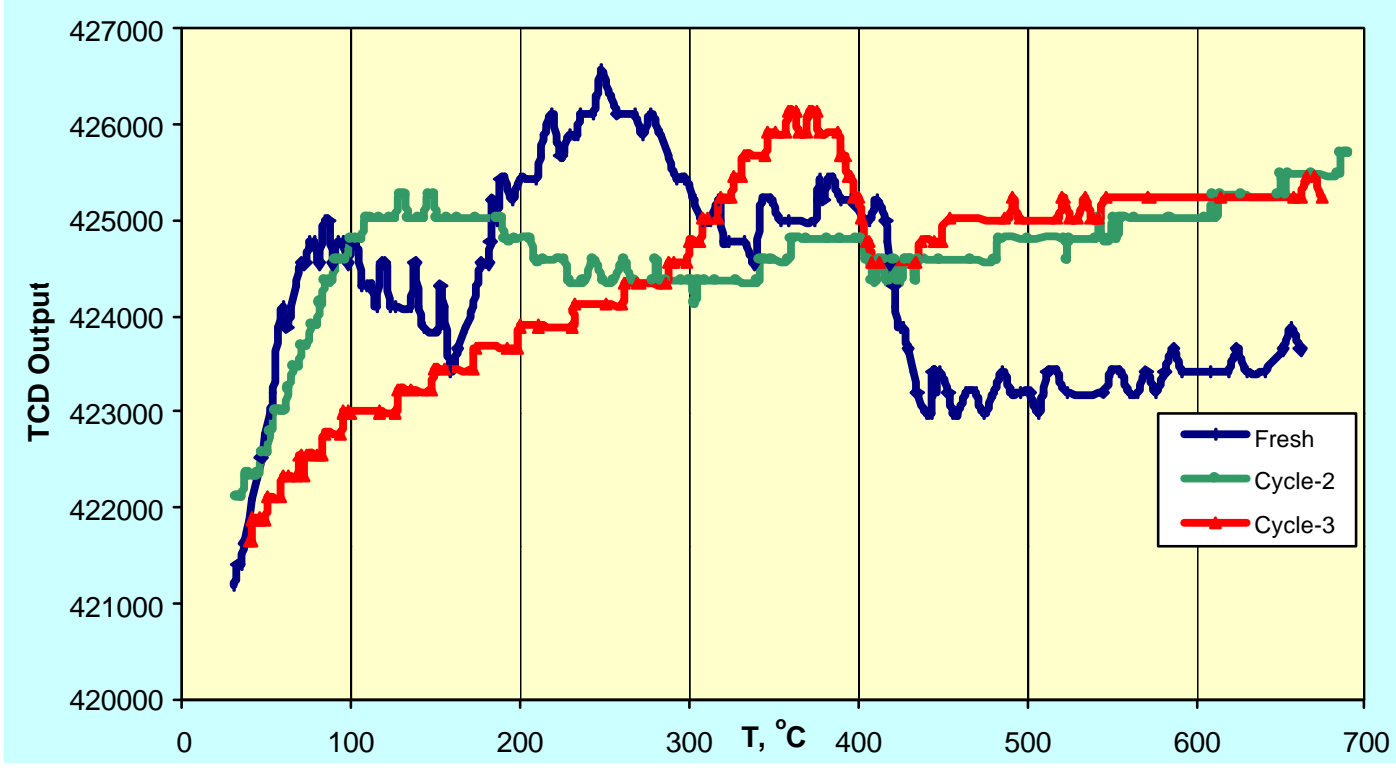

FIGURE 10. Evolved Species During TPD of Fresh Ce2.5Cu7.5 Catalyst with 0.1 $\%$ Rh After NO Adsorption. (DTPD001A)

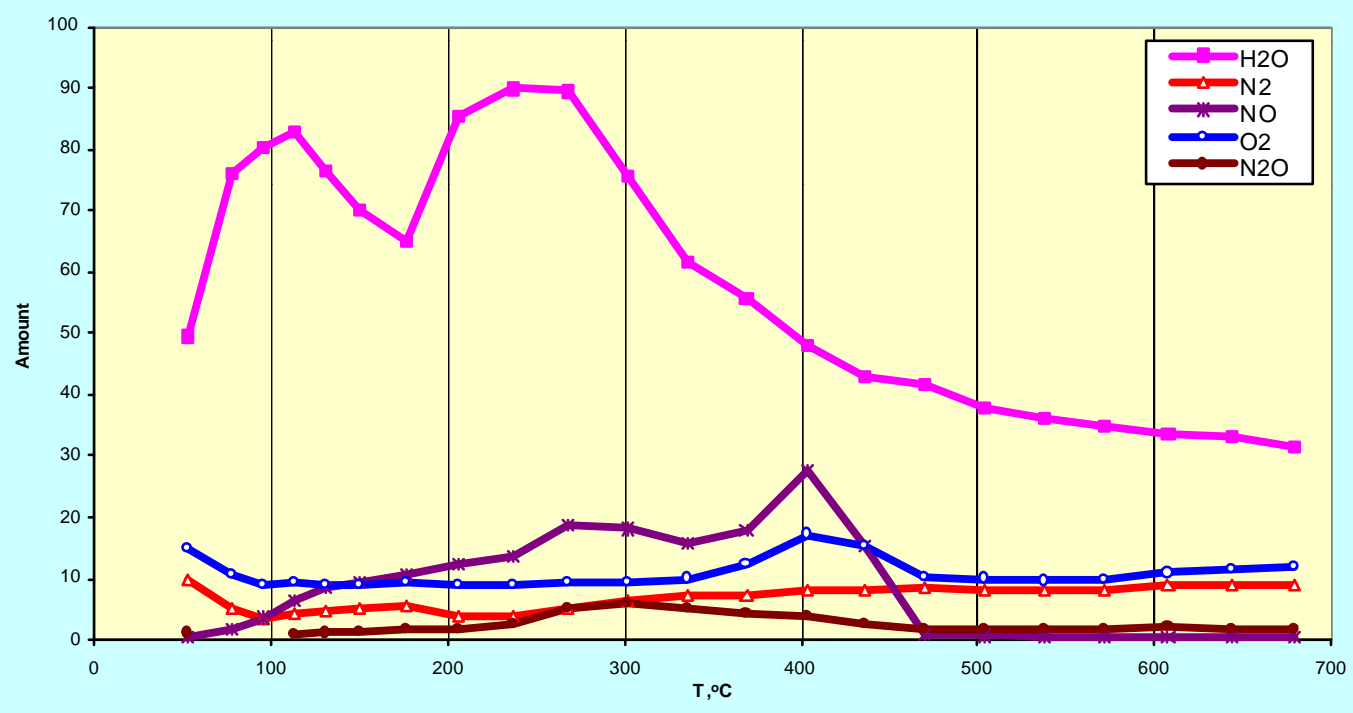


FIGURE 11. Evolved Species During TPD of Ce2.5Cu7.5 Catalyst with $0.1 \% \mathrm{Rh}$ After NO Adsorption. Cycle-2 (DTPD001C)

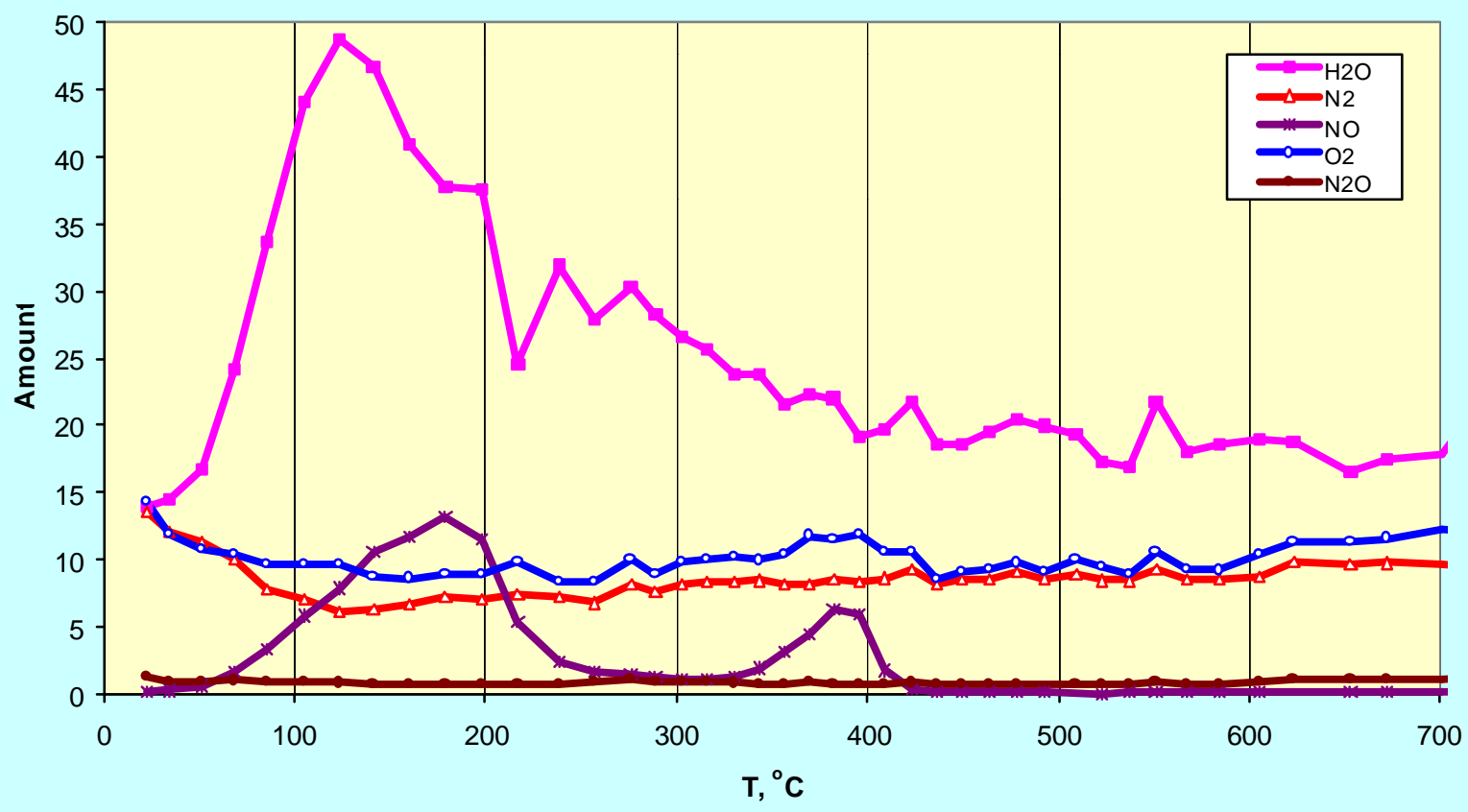

FIGURE 12. Evolved Species During TPD of Ce2.5Cu7.5 Catalyst with $0.1 \% \mathrm{Rh}$ After NO Adsorption. Cycle-3 (DTPD001D)

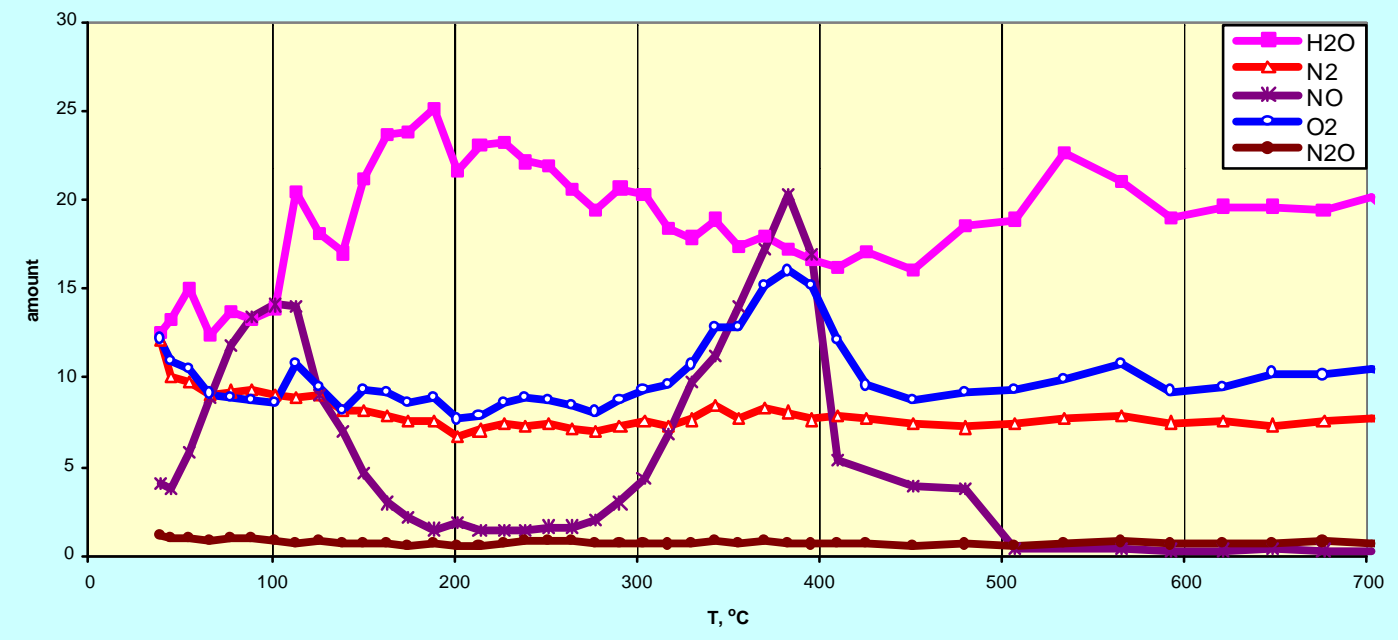


FIGURE 13.TPD of Ce2.5Cu7.5 Catalyst After $\mathrm{NO}$ and $\mathrm{CH}_{4}$ Adsorption (DTPD002F)

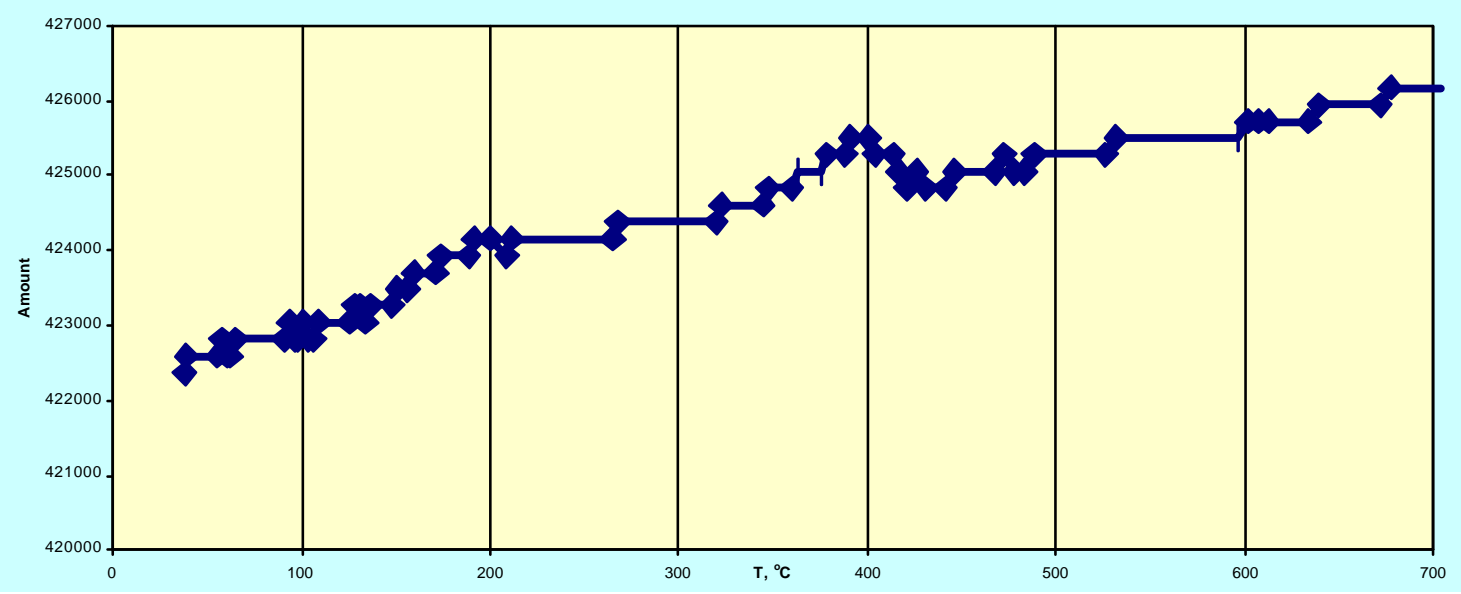

FIGURE 14. Evolved Species During TPD of Ce2.5Cu7.5 Catalyst After Successive $\mathbf{C H}_{4}$ and NO Adsorption (DTPD002F)

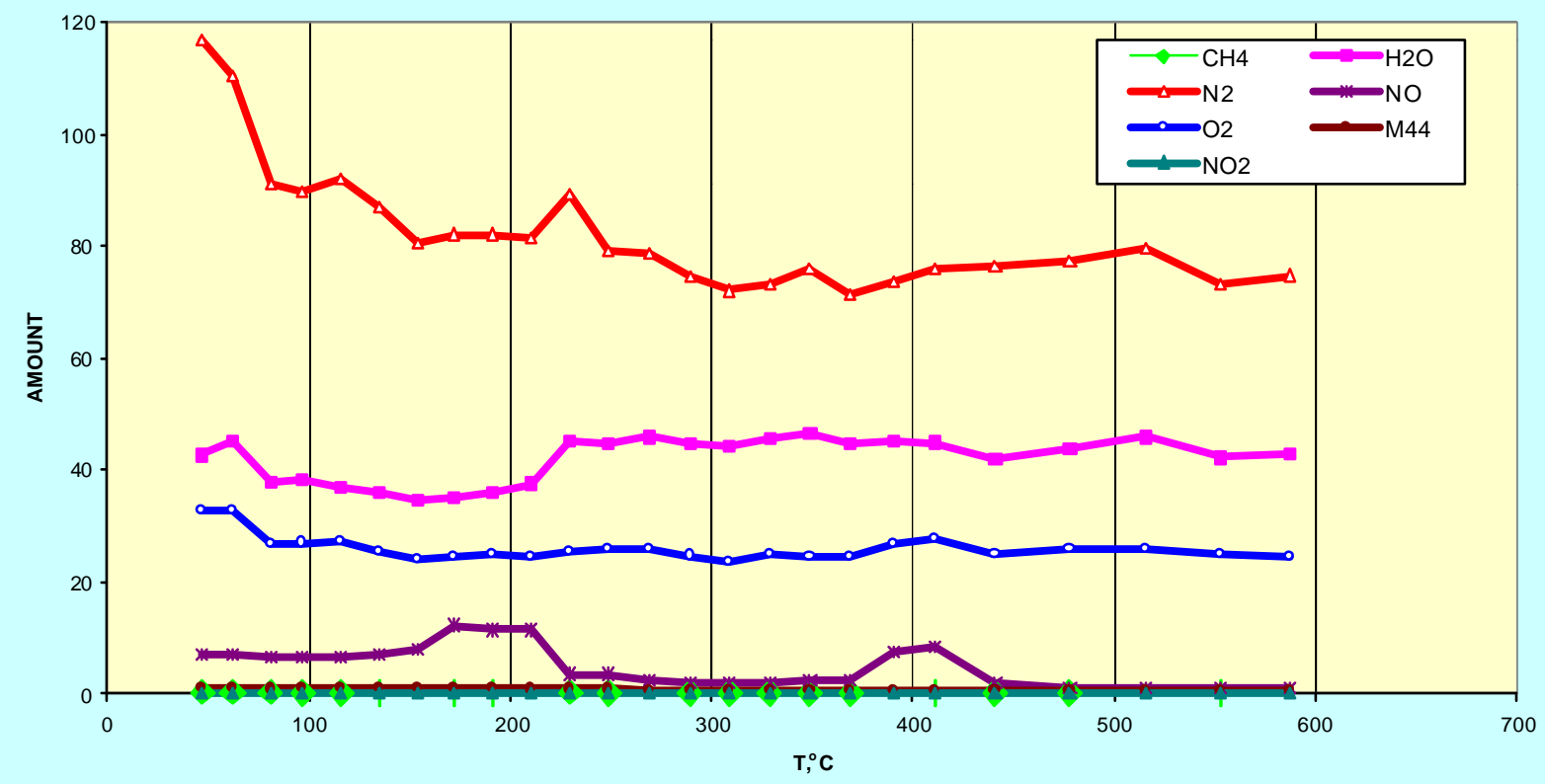


FIGURE 15. TPD of Ce2.5Cu7.5 Catalyst After Successive $\mathrm{O}_{2}$, $\mathrm{NO}$, and $\mathrm{CH}_{4}$ Adsorption (DTPD002H)

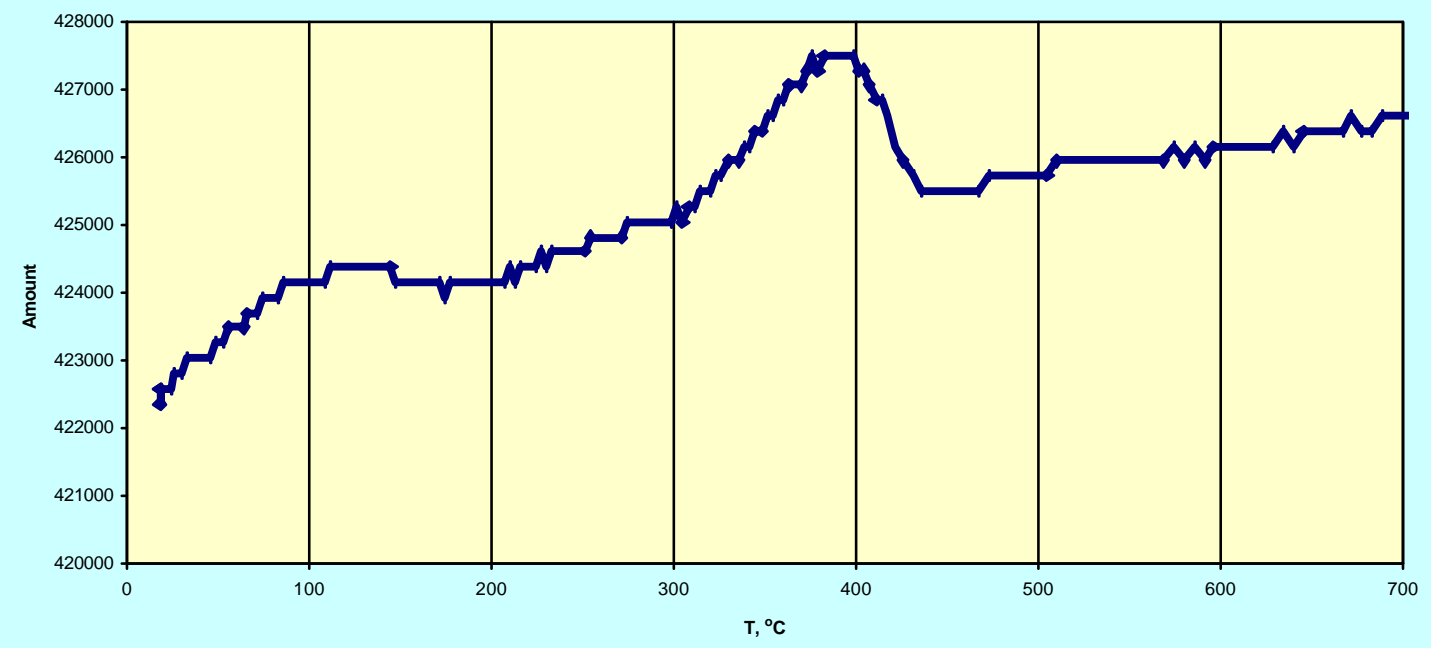

FIGURE 16. Evolved Species During TPD of Ce2.5Cu7.5 Catalyst After Successive $\mathrm{O}_{2}$, NO, and $\mathrm{CH}_{4}$ Adsorption (DTPD002H)

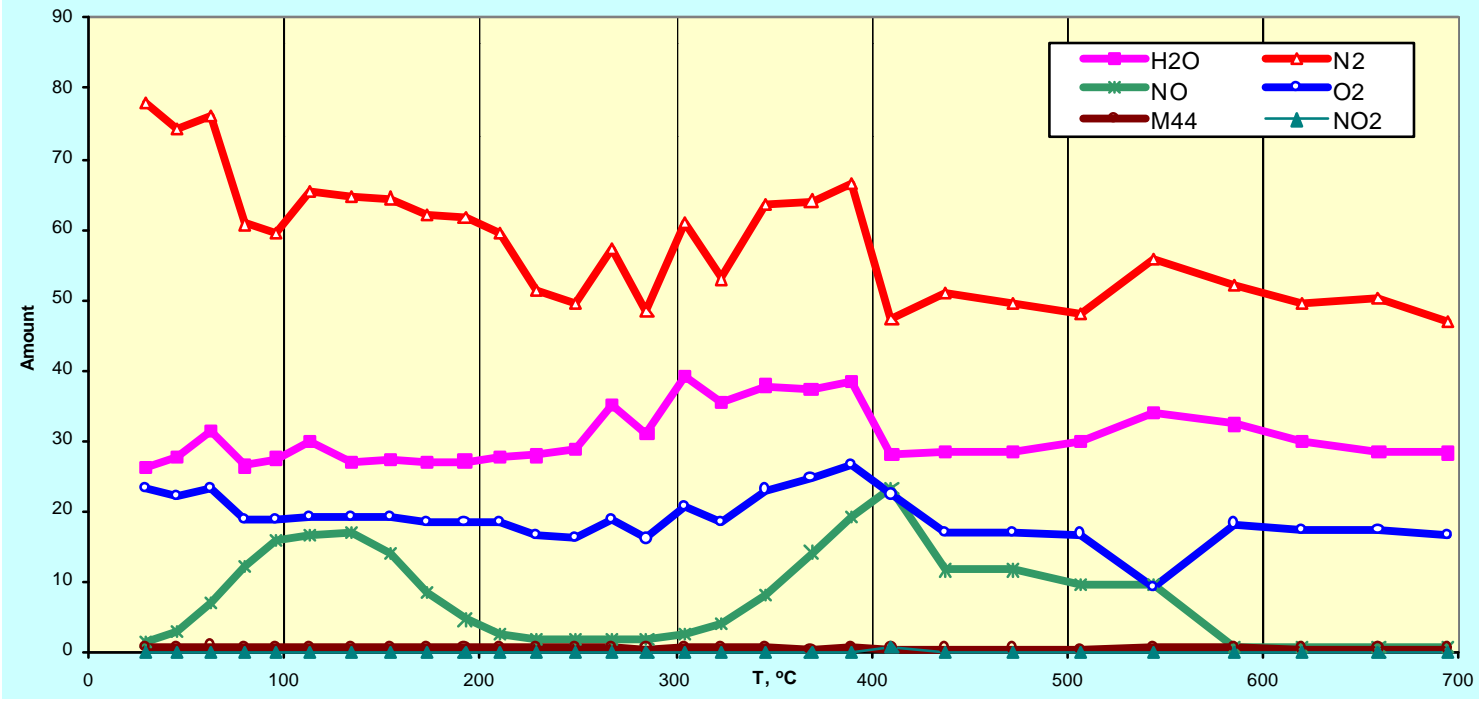


FIGURE 17. TPD OF Ce2.5Cu7.5 Catalyst with $0.1 \%$ Rh After Successive $\mathrm{CH}_{4}$ and NO Adsorption (DTPD001h-TPD)

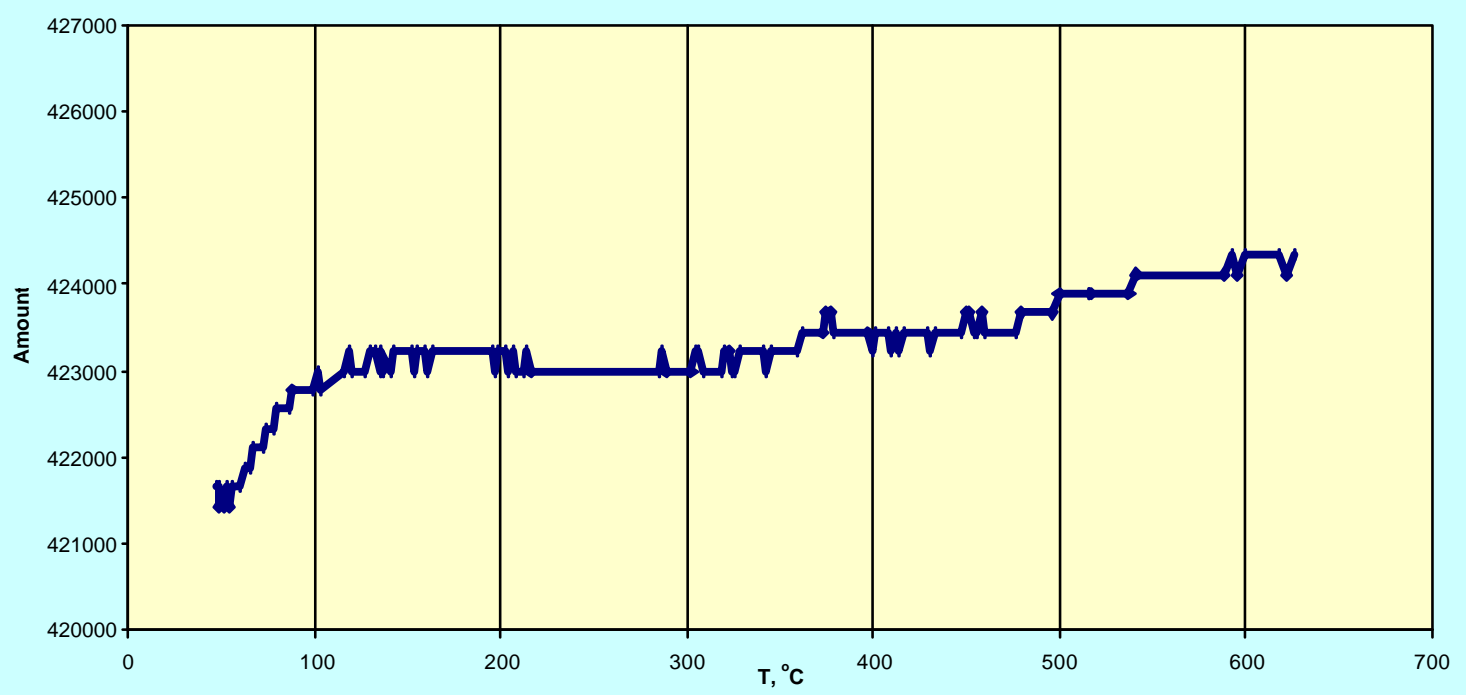

FIGURE 18. Evolved Species During TPD of Ce2.5Cu7.5 Catalyst with $0.1 \%$ Rh After Successive NO, and $\mathrm{CH}_{4}$ Adsorptions (DTPD001H)

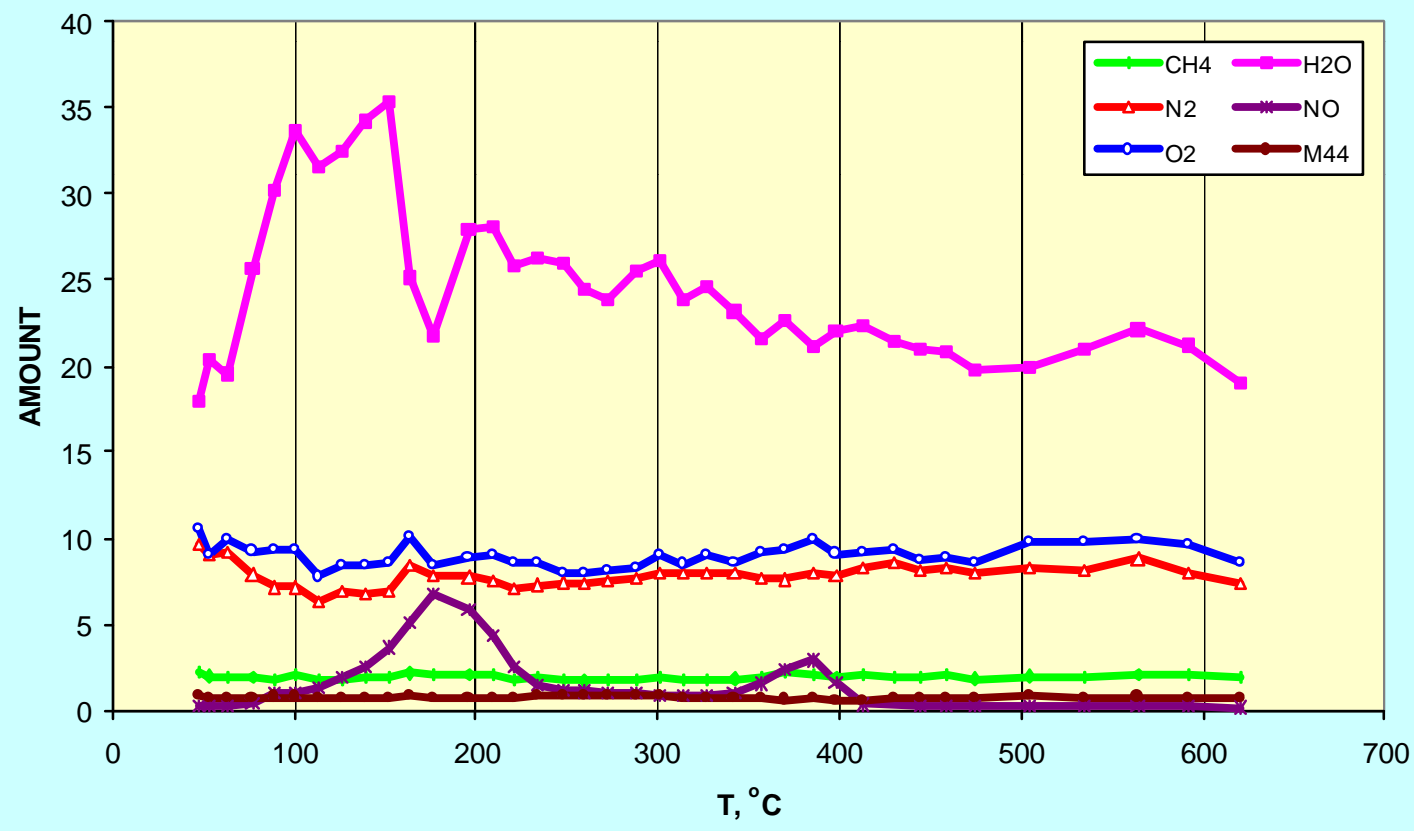

22 
FIGURE 19. TPD of Ce2.5Cu7.5 Catalyst with $0.1 \%$ Rh After

Successive $\mathrm{O}_{2}$, NO, and $\mathrm{CH}_{4}$ Adsorption (DTPD001L-TPD)

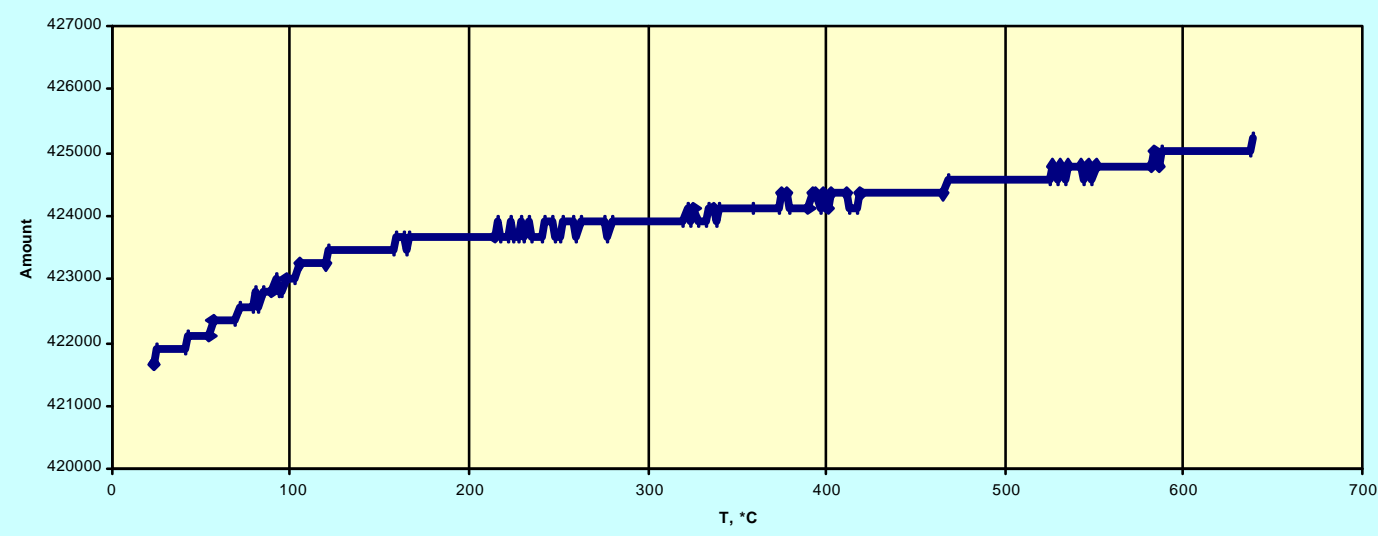

FIGURE 20. Evolved Species During TPD of Ce2.5Cu7.5 Catalyst with $0.1 \%$ Rh After Successive $\mathrm{O}_{2}$, NO, and $\mathrm{CH}_{4}$ Adsorptions (DTPD001L)

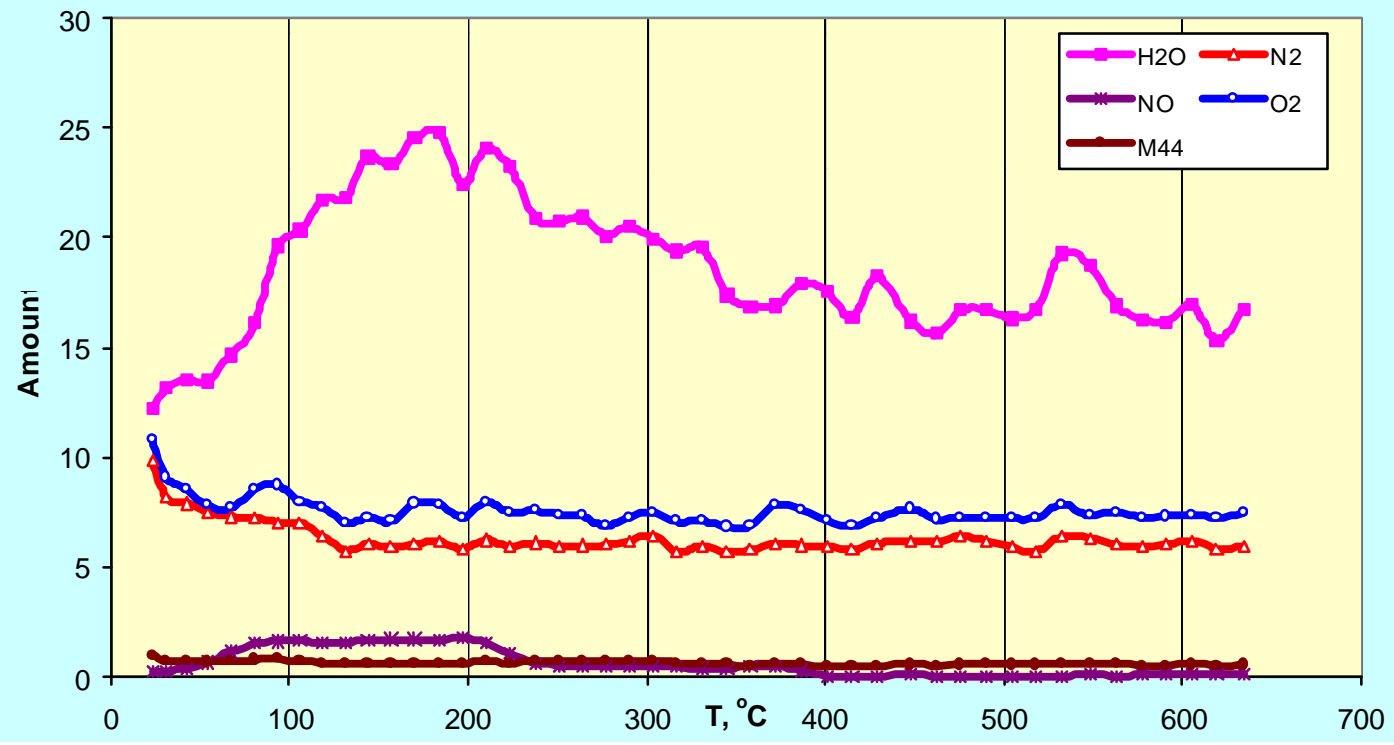


FIGURE 21. TPD of Fresh and Regenerated Ce2.5Cu7.5 Catalyst with $0.1 \%$ Rh After NO Adsorption

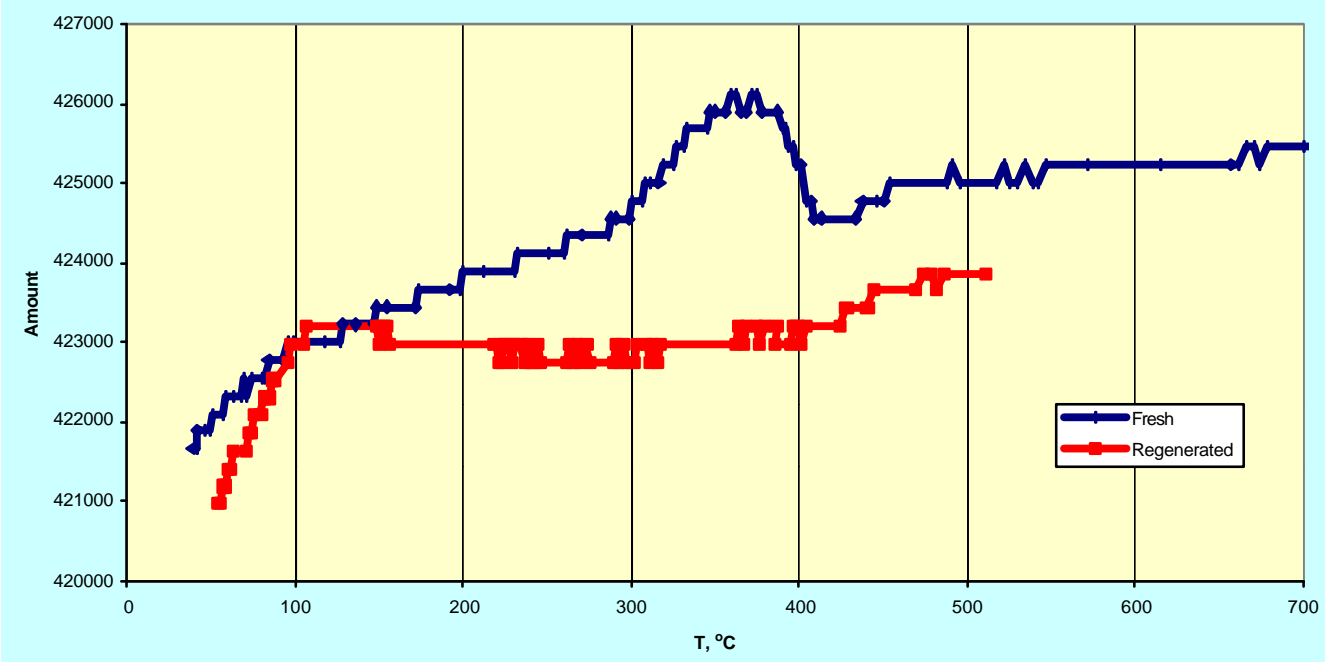

FIGURE 22. Evolved Species During TPD of Regenerated Ce2.5Cu7.5 Catalyst with $0.1 \%$ Rh After NO Adsorption (DTPD001N)

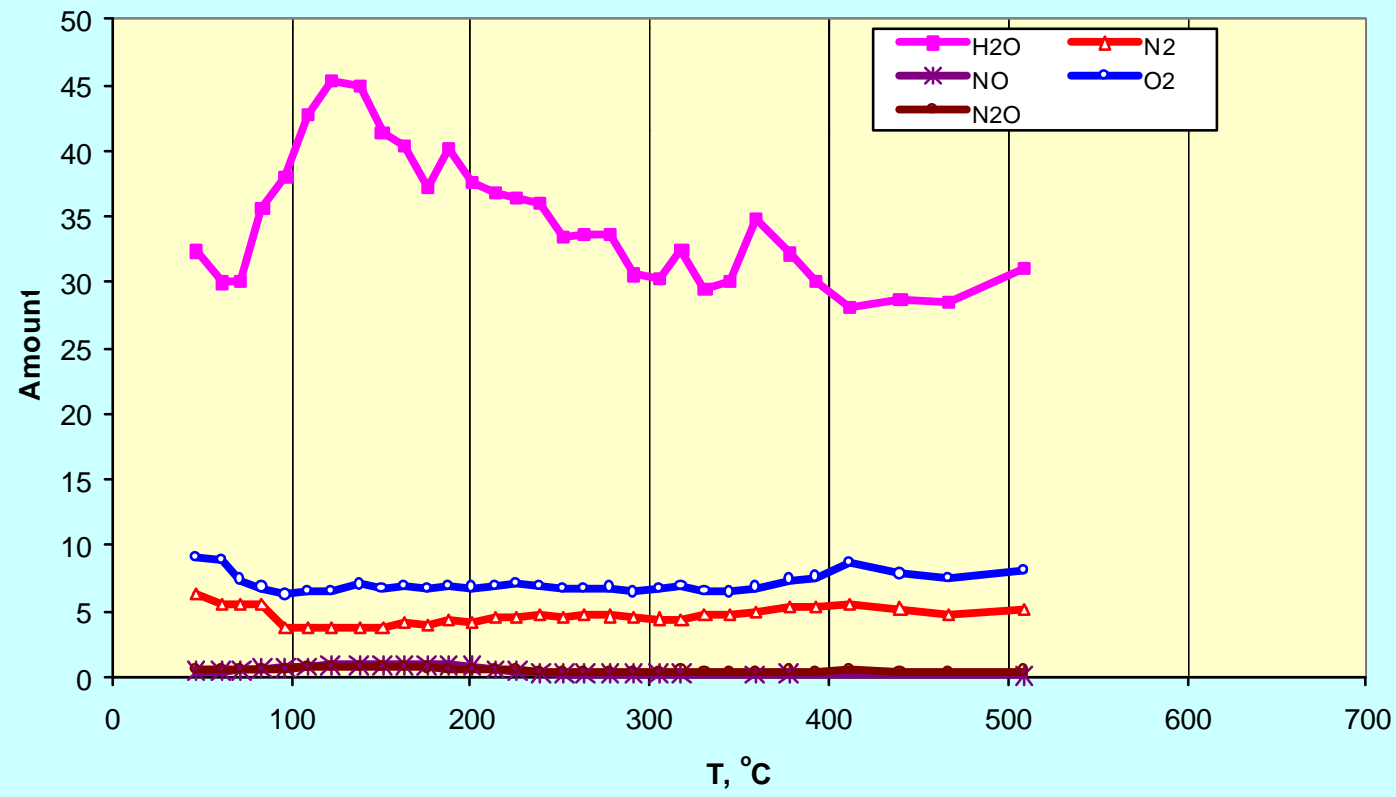


Figures 5-22 exhibit the effect of repeated NO adsorption-TPD to $923 \mathrm{~K}$ on catalyst performance; TPD after successive $\mathrm{CH}_{4}$ and $\mathrm{NO}$ adsorptions; TPD after successive $\mathrm{O}_{2}, \mathrm{NO}$, and $\mathrm{CH}_{4}$ adsorptions; and the possibility of regeneration by oxidation at $873 \mathrm{~K}$ and subsequent treatment with moist $\mathrm{He}$ at $323 \mathrm{~K}$.

When repeated NO adsorption followed by TPD is performed on the fresh unmodified catalyst (SOR10-III; $\mathrm{Cu} / \mathrm{Ce}=3$ ), the main desorption peak is at $423 \mathrm{~K}$ (Figures 5-8). This peak is the result of desorption of water. NO desorption peak appears at $493 \mathrm{~K} . \mathrm{N}_{2} \mathrm{O}$ desorption is limited to temperatures less than $473 \mathrm{~K}$. Significant N2 desorption occurs above $473 \mathrm{~K}$ with the peak at $673 \mathrm{~K}$. For the second and third TPD cycles, the main desorption peak is observed at $673 \mathrm{~K}$ and corresponds to the second NO desorption peak. This peak is not observed on the fresh catalyst. This may imply that the fresh catalyst is more active for NO dissociation. The first NO desorption peaks appears at $433 \mathrm{~K}$ for cycle 2 and $473 \mathrm{~K}$ for cycle 3. $\mathrm{No}_{2} \mathrm{O}$ desorption is observed.

The fresh catalyst (SOR10-III) containing 0.1\% Rh exhibit three desorption peaks at 373, 523, and $673 \mathrm{~K}$ (Figures 9-12). The first two peaks appear to be the result of water desorption and the third peak corresponds to NO desorption. $\mathrm{N}_{2} \mathrm{O}$ desorption peak is at $573 \mathrm{~K}$. For the second TPD cycle, the second peak disappears. In the third TPD cycle, only the third peak remains. Two distinct NO desorption peaks appear (at 453 and $653 \mathrm{~K}$ for cycle 2, and 393 and $653 \mathrm{~K}$ for cycle 3 ). The relative height of the second peak increases with cycling. There is an oxygen desorption peak corresponding to the second NO desorption peak in all cycles. No $\mathrm{N}_{2} \mathrm{O}$ peak is observed in cycle 2 and 3. Low $\mathrm{N}_{2}$ desorption suggests lower activity for NO dissociation.

The TPD after successive $\mathrm{NO}$ and $\mathrm{CH}_{4}$ adsorptions on the fresh unmodified catalyst (SOR10-III; $\mathrm{Cu} / \mathrm{Ce}=3$ ) shows two peaks at $473 \mathrm{~K}$ and $673 \mathrm{~K}$ corresponding to the two NO desorption peaks (Figures 13-14). There is also a uniform $\mathrm{N}_{2}$ desorption, either due to $\mathrm{NO}$ dissociation or reduction by methane or both. The TPD after successive $\mathrm{O}_{2}, \mathrm{NO}$, and $\mathrm{CH}_{4}$ adsorptions also shows two peaks at $403 \mathrm{~K}$ and $673 \mathrm{~K}$ corresponding to the two NO desorption peaks (Figures 15-16). The uniform $\mathrm{N}_{2}$ desorption is also observed.

The TPD after successive $\mathrm{NO}$ and $\mathrm{CH}_{4}$ adsorptions on the catalyst (SOR10-III) modified with 0.1 $\% \mathrm{Rh}$ does not show any distinct peaks because the two NO peaks at $463 \mathrm{~K}$ and $663 \mathrm{~K}$ appear to be 
masked by the uniform water desorption (Figures 17-18). The TPD after successive $\mathrm{O}_{2}, \mathrm{NO}$, and $\mathrm{CH}_{4}$ adsorptions also do not show any distinct peaks (Figures 19-20). There is a single broad NO peak between 353 and $493 \mathrm{~K}$. The significant uniform water desorption is also observed. There is $\mathrm{CO}_{2}$ formation, too, corresponding to $\mathrm{CH}_{4}$ oxidation. This result reinforces the results from the NO-SCR experiments, which revealed that catalysts promoted with rhodium did not have enhanced SCR activities.

Figures 21 and 22 indicate that treatment with oxygen reduces NO adsorption.

\section{CONCLUSIONS}

The NO reduction activity of the catalysts with higher $\mathrm{Cu} / \mathrm{Ce}$ ratio $(\mathrm{Cu} / \mathrm{Ce}=3)$ remained the same when promoted by rhodium compared to the activity of the unpromoted catalyst. However, manganese was an effective promoter, increasing the activity of these catalysts to $21.8 \%$ NO reduction compared to $16.5 \%$ with the unpromoted catalyst.

Promotion with both rhodium and manganese increased the activity of the catalysts having lower $\mathrm{Cu} / \mathrm{Ce}$ ratio $(\mathrm{Cu} / \mathrm{Ce}=1 / 3)$, reaching $20.7 \%$ by rhodium and $23.6 \%$ by manganese. These observations imply that the synergy is due to cerium rather than copper.

NO-TPD on fresh unpromoted catalyst $(\mathrm{Cu} / \mathrm{Ce}=3)$ exhibited a single $\mathrm{NO}$ desorption peak at $493 \mathrm{~K}$; $\mathrm{N}_{2} \mathrm{O}$ desorption was limited to temperatures lower than $473 \mathrm{~K} ; \mathrm{N}_{2}$ desorption increased after $473 \mathrm{~K}$ and showed a peak at $673 \mathrm{~K}$. For the second and third cycles, two NO peaks at 473 and $673 \mathrm{~K}$ were observed. There was no $\mathrm{N}_{2} \mathrm{O}$ desorption during these cycles; and $\mathrm{N}_{2}$ desorption does not increase after $473 \mathrm{~K}$. On this catalyst, the behavior with successive $\left(\mathrm{NO}+\mathrm{CH}_{4}\right)$ and $\left(\mathrm{NO}+\mathrm{CH}_{4}+\mathrm{O}_{2}\right)$ adsorptions was similar to the NO adsorption case.

The fresh catalyst $(\mathrm{Cu} / \mathrm{Ce}=3)$ promoted with $0.1 \%$ Rh exhibited an $\mathrm{NO}$ desorption peak at $673 \mathrm{~K}$, an $\mathrm{N}_{2} \mathrm{O}$ desorption peak at $573 \mathrm{~K}$ and low nitrogen desorption with no peaks. For the second and third cycles, two distinct NO desorption peaks were observed at 453 and $653 \mathrm{~K}$ for the second cycle and at 393 and $653 \mathrm{~K}$ for the third cycle. This indicates lower NO dissociation, this fact being reiterated by low nitrogen desorption. There was no $\mathrm{N}_{2} \mathrm{O}$ peak in the second and third cycles. The TPD with $\mathrm{NO}+\mathrm{CH}_{4}$ was similar to TPD with NO. However, with $\mathrm{NO}+\mathrm{CH}_{4}+\mathrm{O}_{2}$, there is a single $\mathrm{NO}$ desorption peak between 353 and $493 \mathrm{~K}$. Thus, the TPD behavior of the unpromoted SOR10-III catalyst was observed to be different 
from that promoted with $0.1 \%$ rhodium with various adsorbents; it is hypothesized that this variance accounts for the lack of enhancement of SCR activity of this catalyst with promotion by rhodium. The TPD behavior of this catalyst with manganese as the promotor will be performed to interpret the source of activity and the effect of promoters on it for SCR reaction with these catalysts.

\section{Additional Activities}

Several students (Randolph Ashton, Anthony Samuels, Lashonda Martin, and Amy Gay) were employed as undergraduate research students. They were trained in the laboratory to use the TPR/TPD equipment and the reactor setup for the SCR experiments. They have learnt how to use the gas chromatograph and the $\mathrm{NO}_{\mathrm{x}}$ Chemiluminescence equipment.

A poster paper, entitled "Selective Catalytic Reduction of $\mathrm{NO}_{\mathrm{x}}$ by Hydrocarbons on Supported Copper Oxide-Cerium Catalysts" was presented at the $17^{\text {th }}$ North American Catalysis Society Meeting at Toronto, Canada on June 3-8, 2001. A paper entitle "Investigation of Mixed Oxide Catalysts for the Selective Catalytic Reduction of NO by Methane and Propylene" has been accepted for presentation at the AIChE 2001 Annual Meeting at Reno, Nevada on November 4-8, 2001.

\section{FUTURE PLANS}

During next year, it is planned:

1. to do TPD and TPRxN experiments with promoted catalysts;

2. to prepare more promoted catalysts;

3. to perform the selective catalytic reduction (SCR) of NO with methane on promoted catalysts in the microreactor;

4. to do SCR with fuel oil as reductant. 